\section{MS15-P5 Approach to determination the thermal expansion tensor and its interpretation}

Rimma S. Bubnova ${ }^{1,2}$, Vera A. Firsova ${ }^{1}$, Sergey N. Volkov ${ }^{1}$, Stanislav K. Filatov ${ }^{2}$

1. Grebenshchikov Institute of Silicate Chemistry, Russian Academy of Sciences, Makarov Emb. 2, St. Petersburg, 199034 Russia

2. St. Petersburg State University, University Emb. 7/9, St. Petersburg, 199034 Russia

\section{email:rimma_bubnova@mail.ru}

Presently, there is a growing interest in studying the thermal behavior of a substance by the diffraction methods. Thermal expansion is caused by the anharmonicity of the atomic thermal vibrations. Thermal expansion of a crystal lattice is described by a symmetric tensor of the second rank: in the crystalline substances, in accordance with their symmetry, the expansion anisotropy is manifested. In the general case of triclinic crystals, all axes of the expansion tensor are situated arbitrarily with respect to the crystallographic axes, the tensor is characterized by six parameters: the coefficients along three principal mutually orthogonal axes of the tensor $\left(\alpha_{11}, \alpha_{22}, \alpha_{33}\right)$ and three angles, determining the orientation of these axes in the space of the crystal. There is presented a program (Riet_to_Tensor) for determining the thermal expansion tensor of the crystals of any system by a set of experimental diffraction data received using $\mathrm{X}$-ray, synchrotron and other radiations at different temperatures. An algorithm is implemented, which allows carrying out all calculations from the experimental determination of the reflection angles $2 \theta \quad h k l$ to the calculation of the principle values of the thermal extension tensor. The drawing of the 3D-surface of the tensor and its 2D-sections, including the orientation of the tensor axes with respect to the crystallographic axes is provided. The Rietveld method is used to refine cell dimensions and other structure and peak parameters received from *.cif files. Temperature dependence of the cell parameters can be approximated by several types of functions: polynomials, power, Debye and Einstein thermal models. The program has a subprogram to calculate and investigate the temperature dependence of refined parameters, atomic distances and valence angles. As an example the tensor coefficients of borates, silicates and sulphates are presented and results are discussed from high-temperature crystal chemistry.

Acknowledgements. The work is supported by Russian Foundation for Basic Research 15-03-06354. XRD study is performed at X-ray Diffraction Centre of Saint Petersburg State University.

Keywords: In situ study, anisotropy of thermal expansion, lowand high-temperature diffraction, phase transitions, Rietveld refinement

\section{MS15-P6 Structure and electrical properties of $\mathrm{Cr}_{2} \mathrm{O}_{3}-\mathrm{Fe}_{2} \mathrm{O}_{3}-\mathrm{P}_{2} \mathrm{O}_{5}$ and $\mathrm{Cr}_{2} \mathrm{O}_{3}-\mathrm{PbO}-\mathrm{Fe}_{2} \mathrm{O}_{3}-\mathrm{P}_{2} \mathrm{O}_{5}$ glasses and glass-ceramics}

Ana Šantić ${ }^{1}$, Andrea Moguš-Milanković ${ }^{1}, Z_{\text {Željko Skoko }}^{2}$, Delbert E. Day $^{3}$

1. Ruđer Bošković Institute, Zagreb, Croatia

2. Faculty of Science, University of Zagreb, Croatia

3. Missouri University of Science and Technology, Rolla, USA

\section{email: asantic@irb.hr}

Iron phosphate glasses are electronically conducting glasses with polaronic conduction mechanism where conduction takes place by electrons hopping from $\mathrm{Fe}^{2+}$ to $\mathrm{Fe}^{3+}$. Consequently, polaron transport directly depends on $\mathrm{Fe}^{2+} / \mathrm{Fe}_{\text {tot }}$ ratio and overall $\mathrm{Fe}_{2} \mathrm{O}_{3}$ content. On the other hand, electronic conduction ${ }^{3}$ in iron phosphate glass-ceramics depends on (micro)structure, size, shape, distribution and nature of the crystalline phase(s).

The aim of the present study was to investigate structure and electrical properties of iron phosphate glasses and glass-ceramics containing $\mathrm{PbO}$ and $\mathrm{Cr}_{2} \mathrm{O}_{3}$ as a nucleating agent. For that purpose two series of glasses, (43.3-x)PbO-(13.7+x) Fe $\mathrm{O}_{3}-43.0 \mathrm{P}_{2} \mathrm{O}_{5} \quad(0 \leq \mathrm{x} \leq 30 \mathrm{~mol} \%)$ and $\mathrm{xCr}_{2} \mathrm{O}_{3}-(28.3-\mathrm{x}) \mathrm{PbO}-28.7 \mathrm{Fe}_{2} \mathrm{O}_{3}-43.0 \mathrm{P}_{2} \mathrm{O}_{5} \quad(0 \leq \mathrm{x} \leq 10$ mol\%), were prepared by melt quenching technique. The structural changes in glasses were investigated using X-ray diffraction analysis (XRD), Raman and Mössbauer spectroscopies and scanning electron microscopy whereas electrical properties were investigated by impedance spectroscopy.

The Raman spectra and XRD of $\mathrm{PbO}-\mathrm{Fe}_{2} \mathrm{O}_{3}-\mathrm{P}_{2} \mathrm{O}_{5}$ compositions showed that melt underwent partial crystallization when $\mathrm{Fe}_{2} \mathrm{O}_{3}$ content is $\geq 33.7 \mathrm{~mol} \%$. With increasing molar $\mathrm{O} / \mathrm{P}$ ratio and fraction of $\mathrm{Fe}^{2+}$ ions, the length of phosphate units decreases which causes a higher crystallization tendency of the melt. For fully amorphous glasses with $<33.7 \mathrm{~mol} \% \mathrm{Fe}_{2} \mathrm{O}_{3}$, electrical conductivity increases with the increase of $\mathrm{Fe}^{2+} / \mathrm{Fe}_{\text {ti }}$ indicating polaronic transport. On the other hand, the electrical conductivity of the partially crystallized samples decreases despite the increase in $\mathrm{Fe}^{2+}$ fraction which can be attributed to a massive crystallization of several crystalline phases: $\mathrm{Fe}_{7}\left(\mathrm{PO}_{4}\right)_{6}, \mathrm{Fe}_{3}\left(\mathrm{P}_{2} \mathrm{O}_{7}\right)_{2}, \mathrm{Fe}_{2} \mathrm{~Pb}_{3}\left(\mathrm{PO}_{4}\right)$ and $\mathrm{FePO}_{4}$. However, the electrical conductivity of partially crystallized sample with $33.7 \mathrm{~mol} \% \mathrm{Fe}_{2} \mathrm{O}_{3}$ is still considerably high which is related to the fast conduction at the interfaces between crystallites and glassy phase.

The structural studies on the $\mathrm{Cr}_{2} \mathrm{O}_{3}-\mathrm{PbO}-\mathrm{Fe}_{2} \mathrm{O}_{3}-\mathrm{P}_{2} \mathrm{O}_{5}$ glasses showed that the compositions containing up to 4 mol\% $\mathrm{Cr}_{2} \mathrm{O}_{3}$ formed fully amorphous samples while compositions containing 8 and $10 \mathrm{~mol} \% \mathrm{Cr}_{2} \mathrm{O}_{3}$ partially crystallized during cooling to $\mathrm{Fe}_{7}\left(\mathrm{PO}_{4}\right)_{6}, \mathrm{Fe}_{2} \mathrm{~Pb}_{3}\left(\mathrm{PO}_{4}\right)_{4}$ and $\mathrm{Cr}_{2} \mathrm{~Pb}_{3}\left(\mathrm{PO}_{4}\right)_{4}$. The electrical conductivity within this series is a function of the $\mathrm{Fe}^{2+} / \mathrm{Fe}_{\text {tot }}$ ratio and passes through a maximum at 0.48 which $^{\text {tot indicates that the }}$ conduction process is controlled entirely by the polaron transfer between iron sites.

Keywords: glass-ceramics, electrical conductivity 